\title{
Pobreza e desigualdade de renda entre famílias da zona rural de Mato Grosso de 2004 a $2006{ }^{1}$
}

\author{
Poverty and income inequality among families in rural areas of Mato Grosso \\ from 2004 to 2006
}

\author{
Benedito Dias Pereira $^{2 *}$, João Carlos de Souza Maia ${ }^{3}$, Lázaro Camilo Recompensa Joseph², Aprígio Guilherme \\ Miranda Freitas $^{4}$ e Graciela Cristine Oyamada ${ }^{5}$
}

\begin{abstract}
Resumo - Investigou-se a desigualdade da distribuição de renda e a pobreza das famílias residentes nas áreas rurais de Mato Grosso em 2004 e 2006, com base nos microdados da PNAD (IBGE). Em especial, o coeficiente de Gini foi decomposto por fonte de renda, para se identificar a contribuição relativa de determinada fonte de renda na desigualdade da renda total. Dentre os principais resultados encontrados, verificou-se que há elevada desigualdade na distribuição de renda entre as famílias rurais mato-grossenses, que a renda das atividades agrícolas contribui para aumentar essa desigualdade e que essa renda se constitui em variável importante e estratégica para a economia do Estado. Os indicadores também sugerem que houve incremento da pobreza entre as famílias rurais do Estado entre 2004 e 2006.
\end{abstract}

Palavras-chave - Crescimento da Economia. Renda Agrícola. Proporção de Pobres.

\begin{abstract}
Investigates on income distribution inequality and poverty of families living in rural areas of Mato Grosso in 2004 and 2006, based on the microdata of PNAD (IBGE). In particular, the Gini coefficient was broken by source of income to identify the relative contribution of a particular source of income inequality in total income. Among the key findings, it appears that there is high inequality in the income distribution among households in Mato Grosso, that the agriculture income contributes to increasing inequality and that this income is one important and strategic variable for the economy of the state. The indicators also suggest that there was an increase in poverty among rural families of the state between 2004 and 2006.
\end{abstract}

Key words - Growth of Economy. Agriculture Income. Share of Poor.

\footnotetext{
* Autor para correspondência

${ }^{1}$ Recebido para publicação em 20/06/2009; aprovado em 09/10/2010

Pesquisa financiada com recursos da Universidade Federal de Mato Grosso

2Programa de Pós-Graduação em Agronegócios e Desenvolvimento Regional, Faculdade de Economia/UFMT, Rua Jibóia, 129, Apartamento 901, Bairro Consil, 78.048-450, Cuiabá-MT, Brasil, bdp@terra.com.br, camilojoseph@hotmail.com

${ }^{3}$ Programa de Pós-Graduação em Agricultura Tropical, Faculdade de Agronomia e Medicina Veterinária/UFMT, Av. Fernando C. da Costa, s/n, Coxipó, 78.060-900, Cuiabá-MT, Brasil, jotace@terra.com.br

${ }^{4}$ Graduado pela Faculdade de Economia da UFMT, Av. Fernando C. da Costa, s/n, Coxipó, 78.060-900, Cuiabá-MT, Brasil; gguilhermme@gmail.com ${ }_{5}^{5}$ Programa de Pós-Graduação em Agronegócios e Desenvolvimento Regional, Faculdade de Economia/UFMT, Av. Fernando C. da Costa, s/n,

Coxipó, 78.060-900, Cuiabá-MT, Brasil, gracielagra@hotmail.com
} 


\section{Introdução}

Pesquisas sobre desigualdade da distribuição de renda e pobreza vêm exibindo relevância crescente. Essas categorias estão sendo investigadas na economia brasileira por pesquisadores como Hoffmann (2003), Neder (2003), Barros (2006) e Ribeiro e Menezes (2008). Entretanto, as unidades federativas não estão recebendo idêntica atenção. Número reduzido de trabalhos, como Mariano e Neder (2004), Grasel et al. (2008) e Araújo et al. (2008), investigaram essas categorias nesses espaços.

Este estudo tem como objeto a economia rural de Mato Grosso (MT). Em ambiente mundial competitivo e globalizado, exibindo elevada taxa de aumento do PIB, ancorando-se na agropecuária e se alicerçando em modelo primário-exportador, com exportações predominantes de soja in natura, essa economia se assenta em estrutura fundária com elevada desigualdade. Essa estrutura, por oporturno, é majoritariamente habitada por latifúndios modernos, cujas inovações tecnológicas empreendidas, usualmente poupadoras de mão-de-obra, podem estar causando diversos resultados sobre a desigualdade e a pobreza no campo. Nesse quadro, a interação entre esses estabelecimentos e as pequenas propriedades rurais vem desintegrando as pequenas unidades, acentuando a desigualdade e a pobreza (PEREIRA; MENDES, 2002), (PEREIRA, 2010).

Como a desigualdade e a pobreza vinculamse visceralmente ao modelo econômico que lhes são intrínsecos, trabalhos como Veiga (2001), Mariano e Neder (2004), Ferreira et al. (2006) e Araújo et al. (2008) sugerem que modelos com os caracteres acima delineados engendram elevação da desigualdade e da pobreza. Relevantes elementos dessas economias, por oportuno, podem ser observados em Matias et al. (2003), Viana et al. (2006), Pereira et al. (2006) e em Pereira et al. (2009).

Com recorrência aos microdados da PNAD (Pesquisa Nacional por Amostra de Domicílios), do IBGE, como objetivo geral, procura-se avançar na compreensão da economia rural de MT, estimando-se e analisando-se indicadores de pobreza e desigualdade da distribuição de renda entre famílias. Como objetivos específicos, com destaque para a média, estimam-se estatísticas das fontes de renda (Agrícola, Não Agrícola, Aposentadoria e Pensões, Juros e Aluguéis, e Trabalho Secundário e Outros Trabalhos). Em seguida, mensura-se proporção das famílias que recebem e das que não recebem dessas fontes. Logo após, juntamente com estimativa da razão correlação da fonte de renda, calcula-se participação de cada fonte na renda total. Também se estimam índices de Gini das famílias que residem na zona rural, assim como das que auferem dessas fontes. Através do coeficiente de concentração relativa, em seqüência, verifica-se se cada dessas fontes atua para aumentar a desigualdade, além de se investigar a contribuição relativa de cada fonte na desigualdade da renda total. Por fim, mensuram-se os seguintes indicadores de pobreza: proporção de pobres, hiato ou incidência de pobreza e o índice de Sen.

Como conseqüência das mais destacadas características da economia de MT acima apontadas, assim como das suas mutações vivenciadas entre 2004 e 2006, é natural que determinadas hipóteses tenham mais aderência às relações sociais e econômicas dessa ambiência. Nesses termos, além de se prever seu incremento durante o biênio mencionado, formula-se a hipótese que, no conjunto das fontes de renda, a Agrícola registrou a maior média. Além disso, muito provavelmente evidenciando fração com trajetória ascendente, presume-se que a maioria das famílias investigadas recebe renda Agrícola. Ademais, supostamente com variação crescente, imagina-se que essa mesma fonte registrou a maior parcela na renda total. Em paralelo, essa fonte deve ter respondido por progressivo e pelos mais elevados coeficientes de Gini, tanto dentre as famílias residentes na zona rural quanto dentre as que recebem das fontes de renda. Nesse cenário, também se prevê que, além de ter respondido por crescente e pela maior fração da desigualdade, a renda Agrícola exerceu efeito positivo ou direto sobre a desigualdade da renda total. Por fim, ainda como decorrência dos caracteres citados, formula-se a hipótese que a pobreza rural se elevou durante o biênio ora investigado.

\section{Material e métodos}

Nas bases de dados de pessoas da PNAD alusivas a 2004 e 2006 separam-se as informações amostrais para as famílias residentes nas áreas rurais do Estado. As definições de rural e urbano se alicerçam no tratamento dado pelo IBGE ao tema, fundamentado na legislação municipal que delimita o perímetro urbano e, conseqüentemente, a população nele residente. Segundo a Metodologia da PNAD, a renda mensal familiar é obtida através da soma dos rendimentos dos componentes da família, excluindo-se o rendimento das pessoas cuja condição seja pensionista, empregado doméstico ou parente do empregado doméstico.

A renda mensal familiar, reafirmando-se, é subdividida em cinco componentes ou fontes de renda: trabalho principal das atividades agrícolas, atividades não agrícolas, trabalhos secundários e outros trabalhos, aposentadorias e pensões e, por último, juros e aluguéis. O IBGE considera como trabalho principal da semana de referência o único trabalho que a pessoa teve nessa semana (MARIANO; NEDER, 2004). De acordo com o IBGE, além dessas, há outra fonte de renda: "Doações". Todavia, nenhuma família residente na zona rural de MT, nos dois anos investigados, recebeu dessa fonte. 
Ainda segundo o IBGE, as atividades não agrícolas são aquelas exercidas na indústria de transformação, na indústria da construção, nas outras atividades industriais, no comércio de mercadorias, na prestação de serviços, serviços auxiliares da atividade econômica, no transporte e comunicação social, administração pública e, finalmente, em outras atividades mal definidas ou não declaradas. A seguir comenta-se sobre os principais procedimentos e indicadores estatísticos adotados.

\section{Desigualdade da distribuição de renda}

\section{Índice de Gini}

O índice de Gini (G), medida adimensional, estimado a partir da Curva de Lorenz, como é de amplo conhecimento, é uma das ferramentas mais utilizadas no cálculo de desigualdades. A Curva de Lorenz, formada pelos pontos que unem as proporções acumuladas da renda às correspondentes proporções acumuladas da população pesquisada, é composta por duas áreas: uma de concentração efetiva (ACE) e outra de concentração máxima (ACM). O índice de Gini é calculado por intermédio da razão entre essas duas áreas:

$\mathrm{G}=\frac{\mathrm{ACE}}{\mathrm{ACM}}$

Como a Curva de Lorenz situa-se num retângulo quadrado de lado igual a 1, verifica-se que: $\mathrm{ACM}=0,5 . \mathrm{O}$ índice de Gini, desse modo, é equivalente ao dobro da área de concentração efetiva (ACE):

$\mathrm{G}=2 \mathrm{ACE}$

A concentração efetiva, por sua vez, é obtida subtraindo-se a área $\mathrm{S}$ sob a curva de Lorenz da área de concentração máxima:

$\mathrm{CE}=0,5-\mathrm{S}$

Substituindo-se (3) em (2):

$\mathrm{G}=1-2 \mathrm{~S}$

Como se está diante de uma distribuição discreta, a área $\mathrm{S}$ é a soma das áreas dos $n$ trapézios possíveis, definidos pelos diversos níveis de renda. Um desses trapézios tem como bases $\mathrm{Y}_{\mathrm{i}}$ e $\mathrm{Y}_{\mathrm{i}-1}$ e como altura $\mathrm{X}_{\mathrm{i}}-\mathrm{X}_{\mathrm{i}-1}$. Assim, de acordo com Hoffmann (2006), a área $\mathrm{S}$ é dada por:

$$
\mathrm{S}=\sum_{\mathrm{i}=0}^{\mathrm{n}} \mathrm{S}_{\mathrm{i}}=\left(\frac{1}{2}\right)\left(\mathrm{Y}_{\mathrm{i}}+\mathrm{Y}_{\mathrm{i}-1}\right)\left(\mathrm{X}_{\mathrm{i}}+\mathrm{X}_{\mathrm{i}-1}\right)
$$

Substituindo-se (5) em (4):

$$
\begin{aligned}
\mathrm{G}=1-\sum_{\mathrm{i}=0}^{\mathrm{n}} \mathrm{S}_{\mathrm{i}} & =\left(\frac{1}{2}\right)\left(\mathrm{Y}_{\mathrm{i}}+\mathrm{Y}_{\mathrm{i}-1}\right)\left(\mathrm{X}_{\mathrm{i}}+\mathrm{X}_{\mathrm{i}-1}\right) \\
\text { onde } 0 & <\mathrm{G}<1 .
\end{aligned}
$$

\section{Decomposição da desigualdade por fontes de renda}

A decomposição aditiva do índice de Gini por fontes de renda fundamenta-se em Fei et al. (1978). Alguns trabalhos, dentre os quais Neder e Silva (2004) e Mariano e Neder (2004), adotaram essa metodologia para analisar a importância de cada fonte de renda na desigualdade da renda total. Destarte, uma vez que a renda total pode ser decomposta pelas diversas fontes, isto é, se:

$$
\mathrm{Y}=\sum_{\mathrm{k}=1}^{\mathrm{n}} \mathrm{Y}_{\mathrm{k}}=\left(\mathrm{Y}_{1}+\mathrm{Y}_{2}+\mathrm{Y}_{3}+\ldots+\mathrm{Y}_{\mathrm{k}}\right)
$$

O coeficiente de Gini da renda total $\mathrm{G}(\mathrm{Y})$ pode ser estimado por intermédio da identidade

$$
\mathrm{G}(\mathrm{Y})=\sum_{\mathrm{k}-1}^{\mathrm{n}}\left(\mathrm{S}_{\mathrm{k}} \mathrm{R}_{\mathrm{k}} \mathrm{G}\left(\mathrm{Y}_{\mathrm{k}}\right)\right)
$$

Em (8), enquanto $G\left(Y_{k}\right)$ indica o coeficiente de Gini entre as famílias que recebem a fonte $\mathrm{k}, \mathrm{S}_{\mathrm{k}}$ aponta a participação da fonte $\mathrm{k}$ na renda total, obtida por intermédio da expressão:

$$
\mathrm{S}_{\mathrm{k}}=\frac{\mu_{\mathrm{k}}}{\mu}
$$

onde $\mu_{\mathrm{k}}$ denota a renda média da fonte $\mathrm{k}$, e $\mu$, a renda média da renda total. A variável $\mathrm{R}_{\mathrm{k}}$, a "correlação Gini” entre a renda total e k, a qual é definida por:

$$
\mathrm{R}_{\mathrm{k}}=\frac{\operatorname{Cov}\left[\mathrm{Y}_{\mathrm{k}} \mathrm{F}(\mathrm{Y})\right]}{\operatorname{Cov}\left[\mathrm{Y}_{\mathrm{k}} \mathrm{F}\left(\mathrm{Y}_{\mathrm{k}}\right)\right]}
$$

Nessa equação, Cov $\left[\mathrm{Y}_{\mathrm{k}} \mathrm{F}(\mathrm{Y})\right]$ mede a covariância entre $\mathrm{k}$ e o rank da renda total e $\operatorname{Cov}\left[\mathrm{Y}_{\mathrm{k}} \mathrm{F}\left(\mathrm{Y}_{\mathrm{k}}\right)\right]$ afere a covariância entre $\mathrm{k}$ e o rank dessa fonte de renda. Pode-se decompor o índice de Gini da fonte k em duas parcelas:

$$
\mathrm{G}\left(\mathrm{Y}_{\mathrm{k}}\right)=\left(1-\mathrm{p}_{\mathrm{k}}\right)+\mathrm{p}_{\mathrm{k}} \mathrm{G}\left(\mathrm{Y}_{\mathrm{k}}\right)
$$

Em (11), enquanto $p_{k}$ indica a proporção das famílias contempladas com a fonte $\mathrm{k},\left(1-\mathrm{p}_{\mathrm{k}}\right)$ mede a proporção das famílias sem o recebimento dessa fonte de renda. Diante disso, como obtido em (12), verifica-se se determinada fonte atua no sentido de elevar ou contrair a desigualdade da renda total: 


$$
G\left(Y_{k}\right)=\frac{R_{k} G\left(Y_{k}\right)}{G(Y)}
$$

A participação atribuída a cada fonte é medida por:

$$
I_{k}=\frac{S_{k} G_{k} R_{k}}{G(Y)}
$$

Assim sendo, é imediato se inferir que a contribuição da fonte $\mathrm{k}$ na desigualdade total será tão maior quanto mais expressiva for essa parcela (SON, 2004) (MARIANO; NEDER, 2004).

\section{Indicadores de pobreza}

\section{Linha de pobreza $(Z)$}

A estimativa da pobreza, inicialmente, requer a adoção de uma linha de pobreza Z. Essa é uma questão intrinsecamente polêmica, porquanto, de modo geral, as linhas de pobreza são estabelecidas de forma arbitrária. A linha de pobreza utilizada foi definida como metade do salário mínimo vigente em cada ano estudado. Semelhante procedimento foi adotado por Mariano e Neder (2004). Como ilustração, ainda inexiste estudo que especifique a linha de pobreza na zona rural mato-grossense.

\section{Proporção de pobres (H)}

A proporção de pobres na população total se constitui em medida, amplamente conhecida e usada, de pobreza; com $\mathrm{Z}$ denotando a linha de pobreza, $\mathrm{K}$ o número de pessoas com renda inferior a $\mathrm{Z}$, e $\mathrm{N}$ a população pesquisada. Define-se a proporção de pobres $(\mathrm{H})$ por intermédio de

$$
\mathrm{H}=\frac{\mathrm{K}}{\mathrm{N}}
$$

sendo $0<\mathrm{H}<1$. Por lógico, é considerada pobre a família com renda inferior à linha de pobreza.

\section{Hiato ou incidência de pobreza (I)}

Seja $Y_{i}$ a renda do i-ésimo indivíduo ou família pobre, define-se como hiato ou incidência da pobreza (I) a razão entre a soma das defasagens de renda de todos os pobres e o produto da linha de pobreza pelo número de pobres:

$$
I=\frac{1}{Z K}+\sum_{i=1}^{k}(Z-Y)
$$

onde $0<\mathrm{I}<1$.
Em (15), o hiato entre a renda per capita de uma família i e a linha de pobreza $\left(Y_{i}-Z\right)$ aponta a insuficiência de renda dessa unidade em relação à linha de pobreza. Essa identidade também pode ser escrita como:

$$
\mathrm{I}=1-\frac{\mathrm{m}}{\mathrm{Z}}
$$

Em (16), I situa-se entre zero e um e m denota a renda média dos pobres. Em um extremo $\mathrm{I}=0$ e $\mathrm{m}=\mathrm{Z}$, implicando a inexistência de pobreza; no outro extremo $\mathrm{I}=1$ e $\mathrm{m}=0$, apontando que a carência é máxima quando a renda investigada é igual a zero (NEDER; SILVA, 2004).

\section{Índice de pobreza de Sen $(P)$}

Um índice sintético de pobreza deve contemplar três variáveis: a proporção de pobres na população $(\mathrm{H})$; a incidência ou intensidade da pobreza (I), que mede o déficit de renda dos pobres em relação à linha de pobreza (Z); e a desigualdade na distribuição de renda entre os pobres, medida, por exemplo, pelo índice de Gini. O índice de pobreza $(\mathrm{P})$, de sem, abriga essas três dimensões. Em resumo, como, diferentemente de $\mathrm{H}$ e I, $\mathrm{P}$ incorpora a desigualdade $(\mathrm{G})$ entre os pobres. Esse índice também é utilizado para se medir a pobreza das famílias residentes nas áreas rurais de MT. De acordo com Hoffmann (2006), o cálculo desse índice pode ser realizado por:

$\mathrm{P}=\mathrm{H}[\mathrm{I}+(1-\mathrm{I}) \mathrm{G}$

\section{Resultados e discussão}

Esse item está dividido em duas partes. Na primeira, inicialmente, discutem-se as estatísticas descritivas de cada fonte de renda, a participação dessas fontes na renda total e a razão correlação da fonte de renda. Esse último indicador, relembrando, revela se os valores das fontes de renda tendem a crescer ou a diminuir com a renda familiar total. Após isso, por intermédio do coeficiente de Gini, mensura-se a concentração em cada fonte de renda das famílias que residem na zona rural de MT e das famílias que recebem dessas mesmas fontes. Posteriormente, através do coeficiente de concentração relativa, investiga-se se dada fonte de renda contribuiu para diminuir ou aumentar a desigualdade da distribuição de renda e calcula-se a participação da fonte na desigualdade de renda total, ou seja, mensura-se o quanto cada fonte de renda responde pela desigualdade total. Na segunda e última parte, estimam-se e analisam-se as estatísticas de pobreza.

\section{Desigualdade da distribuição de renda}

Em primeiro lugar, na Tabela 1, consta o resumo estatístico dos dados analisados. Mais especificamente, 
Tabela 1 - Estatísticas descritivas das fontes de renda familiar: zona rural de Mato Grosso: 2004 e 2006

\begin{tabular}{lrrrrrrrr}
\hline & \multicolumn{3}{c}{2004} & & & & \multicolumn{2}{c}{2006} \\
\cline { 2 - 9 } \multicolumn{1}{c}{ Renda } & Média & Desvio & Mínimo & Máximo & Média & Desvio & Mínimo & Máximo \\
& $\mathrm{R} \$$ & Padrão & $\mathrm{R} \$$ & $\mathrm{R} \$$ & $\mathrm{R} \$$ & Padrão & $\mathrm{R} \$$ & $\mathrm{R} \$$ \\
\hline Agrícola & 159,69 & 502,14 & 0,00 & $12.000,00$ & 168,57 & 431,59 & 0,00 & $8.000,00$ \\
Não Agrícola & 53,54 & 298,45 & 0,00 & $8.000,00$ & 80,46 & 382,48 & 0,00 & $8.000,00$ \\
Aposentadorias e Pensões & 22,12 & 96,96 & 0,00 & $1.494,00$ & 37,45 & 159,69 & 0,00 & $3.400,00$ \\
Juros e Aluguéis & 6,41 & 63,41 & 0,00 & $1.000,00$ & 9,90 & 60,53 & 0,00 & 900,00 \\
Trabalho Secundário e Outros & 6,43 & 108,23 & 0,00 & $2.200,00$ & 4,03 & 54,93 & 0,00 & $1.000,00$ \\
\hline
\end{tabular}

Fonte: Elaboração própria com base na Pesquisa Nacional por Amostras de Domicílios (Microdados) (IBGE): 2004 e 2006

nela se inserem estatísticas descritivas (valor mínimo, médio, máximo e desvio padrão) da renda familiar per capita, assim como das fontes de renda, recordando-se que, nesse caso, a hipótese é que a renda Agrícola aumentou de 2004 a 2006 e que essa fonte exibiu a maior média no conjunto das médias das fontes de renda.

Constata-se que a média da renda Agrícola é a maior dentre as médias das fontes de renda. Logo, a hierarquia ou posicionamento desse indicador no conjunto das rendas ratifica a supremacia da renda Agrícola sobre as demais fontes de renda. Ainda vê-se que, de 2004 a 2006, a renda média Agrícola aumentou. Situada logo abaixo da renda Agrícola, observa-se que a média da renda Não Agrícola igualmente ascendeu no período. Assim, os resultados da Tabela 1 se conformam à hipótese do Artigo e apontam a importância relativa da renda Agrícola na zona rural do Estado.

Após essas análises, na Tabela 2, constam percentuais das famílias que receberam e das que não auferiram dessas diversas fontes de renda. Nesse caso, a hipótese é que a renda Agrícola respondeu por crescente e pela maior fração das famílias contempladas pelas várias fontes de renda.

Nota-se que, com percentual bem superior às demais, merece destaque a proporção das famílias que auferiram a renda Agrícola, não obstante ser levemente declinante de 2004 a 2006. Por sua vez, a percentagem das famílias que receberam renda Não Agrícola, além de ser substancialmente menor que a das famílias que foram contempladas pelas rendas Agrícolas, aumenta no biênio. Em adição, enquanto em torno de $10 \%$ das famílias rurais declararam receber algum tipo de renda de Aposentadorias e Pensões, proporção inferior dessas mesmas famílias receberam renda de Juros e Aluguéis. Também se vê que somente $1 \%$ das famílias rurais foi contemplada com renda de Trabalho Secundário e Outros Trabalhos. Em síntese, nota-se que a percentagem das famílias que receberam a renda Agrícola é superior às percentagens das que auferiram das demais fontes, a despeito de exibir pequeno declínio no intervalo de tempo em estudo. Por conseguinte, depreende-se que a hipótese foi parcialmente refutada pelas evidências empíricas.

Tabela 2 - Sumário estatístico das famílias que recebem ou não da fonte de renda: zona rural de Mato Grosso: 2004 e 2006

\begin{tabular}{lcccc}
\hline \multirow{2}{*}{ Renda } & \multicolumn{2}{c}{2004} & \multicolumn{2}{c}{2006} \\
\cline { 2 - 5 } & $\begin{array}{c}\text { Porcentagem } \\
\text { das famílias que } \\
\text { recebem a fonte de } \\
\text { renda }\end{array}$ & $\begin{array}{c}\text { Porcentagem das } \\
\text { famílias que não } \\
\text { recebem a fonte } \\
\text { de renda }\end{array}$ & $\begin{array}{c}\text { Porcentagem } \\
\text { das famílias que } \\
\text { recebem a fonte } \\
\text { de renda }\end{array}$ & $\begin{array}{c}\text { Porcentagem de } \\
\text { famílias que não } \\
\text { recebem a fonte de } \\
\text { renda }\end{array}$ \\
\hline Agrícola & $p_{k}$ & $1-p_{k}$ & $p_{k}$ & $1-p_{k}$ \\
Não Agrícola & $35,46 \%$ & $64,54 \%$ & $33,50 \%$ & $66,50 \%$ \\
Aposentadorias e Pensões & $11,49 \%$ & $88,51 \%$ & $13,18 \%$ & $86,82 \%$ \\
Juros e Aluguéis & $9,30 \%$ & $90,70 \%$ & $10,93 \%$ & $89,07 \%$ \\
Trabalho Secundário e Outros & $5,18 \%$ & $94,82 \%$ & $7,65 \%$ & $92,35 \%$ \\
\hline
\end{tabular}

Fonte: Elaboração própria com base na Pesquisa Nacional por Amostras de Domicílios (Microdados) (IBGE): 2004 e 2006 
Em seqüência, a partir dos dados da Tabela 3, analisa-se a participação de cada fonte de renda na renda total e a razão correlação da fonte de renda. Em particular, imaginando-se obter a razão correlação positiva para todas as fontes de renda, indicando, nessa circunstância, que a renda familiar total se eleva quando o valor das fontes de renda progride, a hipótese foi que a renda Agrícola aumentou de 2004 a 2006 e respondeu pela maior parcela na renda total.

Observa-se que, como foi pressuposto, os valores da razão correlação para todas as fontes de renda são positivos. Averigua-se que, em 2004, o valor mais elevado da razão correlação é o das Aposentadorias e Pensões, seguido pela renda Agrícola, enquanto que, em 2006, seqüencialmente, predominam as rendas do Trabalho Secundário e Outros Trabalhos e a renda Agrícola. De modo pontual, verifica-se que, apesar de decair em pequena proporção de 2004 a 2006, a renda Agrícola exerceu forte pressão sobre o crescimento da renda total, isto é, essa categoria revelou-se altamente dependente dessa fonte de renda, confirmando a hipótese formulada.
Ressalta-se, além disso, que, em 2006, crescente em relação a 2004, a renda Não Agrícola é a segunda fonte de renda com maior participação na renda total, indicando que as famílias residentes nas áreas rurais do Estado estão cada vez mais empreendendo atividades pluriativas, ou seja, distintas da agrícola. Portanto, “A pluriatividade é um fenômeno através do qual, membros das famílias que habitam no meio rural optam pelo exercício de diferentes atividades, ou mais rigorosamente, pelo exercício de atividades não-agrícolas", como observa Schneider (2001, p.175). Exemplos de atividades pluriativas são as agroindustriais, as de turismo rural, etc.

Uma vez abordados esses temas, logo adiante, estima-se o coeficiente de Gini das famílias residentes nas regiões rurais mato-grossense. Além desses valores, na Tabela 4 estão insertos os resultados do pseudo Gini, isto é, do coeficiente de Gini das famílias que auferem de cada fonte de renda. No caso desses indicadores, as hipóteses foram que os coeficientes associados à renda Agrícola ascenderam e que a renda Agrícola exibiu os maiores valores dentre as fontes de renda.

Tabela 3 - Participação da fonte de renda na renda total e a razão correlação da fonte de renda: zona rural de Mato Grosso: 2004 e 2006

\begin{tabular}{lcccc}
\hline \multirow{2}{*}{ Renda } & \multicolumn{2}{c}{2004} & \multicolumn{2}{c}{2006} \\
\cline { 2 - 5 } & $\begin{array}{c}\text { Participação da } \\
\text { fonte de renda } \\
\text { na renda total }\end{array}$ & $\begin{array}{c}\text { Razão } \\
\text { correlação da } \\
\text { fonte de renda }\end{array}$ & $\begin{array}{c}\text { Participação da } \\
\text { fonte de renda na } \\
\text { renda total }\end{array}$ & $\begin{array}{c}\text { Razão correlação da } \\
\text { fonte de renda }\end{array}$ \\
\hline Agrícola & $S_{k}$ & $R_{k}$ & $S_{k}$ & $R_{k}$ \\
Não Agrícola & 0,644 & 0,539 & 0,561 & 0,555 \\
Aposentadorias e Pensões & 0,215 & 0,440 & 0,268 & 0,313 \\
Juros e Aluguéis & 0,089 & 0,547 & 0,125 & 0,548 \\
Trabalho Secundário e Outros & 0,026 & 0,444 & 0,033 & 0,263 \\
\hline
\end{tabular}

Fonte: Elaboração própria com base na Pesquisa Nacional por Amostras de Domicílios (Microdados) (IBGE): 2004 e 2006

Tabela 4 - Sumário estatístico da decomposição do coeficiente de Gini pelas fontes de renda: zona rural de Mato Grosso: 2004 e 2006

\begin{tabular}{lcccc}
\hline \multirow{2}{*}{ Renda } & \multicolumn{2}{c}{2004} & 2006 \\
\cline { 2 - 5 } & $\begin{array}{c}\text { Gini da } \\
\text { fonte de } \\
\text { renda } G\left(Y_{k}\right)\end{array}$ & $\begin{array}{c}\text { Gini das famílias que } \\
\text { recebem da fonte de } \\
\text { renda } G^{*}\left(Y_{k}\right)\end{array}$ & $\begin{array}{c}\text { Gini da fonte de } \\
\text { renda } G\left(Y_{k}\right)\end{array}$ & $\begin{array}{c}\text { Gini das famílias que } \\
\text { recebem da fonte de } \\
\text { renda } G^{*}\left(Y_{k}\right)\end{array}$ \\
\hline Agrícola & 0,7586 & 0,3193 & 0,7532 & 0,2632 \\
Não Agrícola & 0,9045 & 0,1685 & 0,9061 & 0,2873 \\
Aposentadorias e Pensões & 0,9189 & 0,1279 & 0,9144 & 0,2172 \\
Juros e Aluguéis & 0,9736 & 0,4896 & 0,9611 & 0,4912 \\
Trabalho Secundário e Outros & 0,9936 & 0,3990 & 0,9934 & 0,3608 \\
\hline
\end{tabular}

Fonte: Elaboração própria com base na Pesquisa Nacional por Amostras de Domicílios (Microdados) (IBGE): 2004 e 2006 
As fontes de renda Trabalhos Secundários e Outros Trabalhos, e Juros e Aluguéis, registram os maiores coeficientes de $\mathrm{G}\left(\mathrm{Y}_{\mathrm{k}}\right)$, tanto em 2004, quanto em 2006. Por sua vez, não obstante ter experimentado variação marginal decrescente no biênio e exibido o menor coeficiente de Gini dentre as fontes de renda nesses dois anos, o coeficiente da renda Agrícola pode ser considerado elevado. Por outro lado, os valores do pseudo Gini $\left(\mathrm{G}^{*}\left(\mathrm{Y}_{\mathrm{k}}\right)\right)$ (famílias que recebem de dada fonte de renda), de modo geral, revelam baixa desigualdade. Em resumo, focando-se em $\mathrm{G}\left(\mathrm{Y}_{\mathrm{k}}\right)$, observa-se que todas as fontes de renda exibem elevada desigualdade e, de modo pontual, além de ser descendente de 2004 a 2006, a renda Agrícola possui o menor valor no conjunto das várias fontes de renda, fatos que refutam as hipóteses do Artigo.

Em complemento, por intermédio do coeficiente de concentração relativa, a seguir se investiga se dada fonte de renda contribuiu ou não para aumentar a desigualdade. Por oportuno, recorda-se: se esse valor for igual ou maior que um, a fonte de renda atua no sentido de expandir a desigualdade e inversamente: se o coeficiente for menor do que a unidade, a fonte de renda contribui para contrair essa desigualdade. A hipótese contemplou que a renda Agrícola experimentou ascensão no biênio, além de ter exibido a mais elevada concentração relativa. A Tabela 5 abriga as estatísticas afins.
Percebe-se que as únicas fontes de renda que atuaram para aumentar a desigualdade foram, em 2004: Aposentadorias e Pensões, e Juros e Aluguéis; em 2006: Agrícola, Aposentadorias e Pensões, além de Trabalho Secundário e Outros Trabalhos. Em particular, assim como em 2004, em 2006, as rendas de atividades não Agrícolas pressionaram para baixo a desigualdade, enquanto que, a renda Agrícola, em 2006, exerce efeito contrário sobre a desigualdade. Dessa maneira, conquanto maior que um tão somente no último ano, o coeficiente da renda Agrícola registrou incremento entre os dois anos, por conseguinte, de maneira parcial, esses resultados confirmam a hipótese.

Em adição, quantifica-se a contribuição de cada fonte de renda para a desigualdade da distribuição de renda entre as famílias, visto que, embora o coeficiente de concentração relativa revelar se a fonte de renda atua no sentido de ampliar ou contrair a desigualdade de renda, ele não indica a participação na desigualdade de renda total entre as famílias. Relembra-se que, de acordo com hipóteses do Artigo, a renda Agrícola explana a maior fração da desigualdade da distribuição de renda dentre as várias fontes de renda de forma cada vez mais acentuada. Os resultados dessa análise estão na Tabela 6.

Tabela 5 - Coeficiente de concentração relativa: fontes de renda da zona rural de Mato Grosso: 2004 e 2006

\begin{tabular}{llc}
\hline \multirow{2}{*}{ Renda } & \multicolumn{2}{c}{ Coeficiente de Concentração Relativa $\left(\mathrm{g}_{\mathrm{k}}\right)$} \\
\cline { 2 - 3 } & 2004 & 2006 \\
\hline Agrícola & 0,9891 & 1,0709 \\
Não Agrícola & 0,9636 & 0,7272 \\
Aposentadorias e Pensões & 1,2178 & 1,2851 \\
Juros e Aluguéis & 1,0453 & 0,6491 \\
Trabalho Secundário e Outros Trabalhos & 0,7797 & 1,6921 \\
\hline
\end{tabular}

Fonte: Elaboração própria com base na Pesquisa Nacional por Amostras de Domicílios (Microdados) (IBGE): 2004 e 2006

Tabela 6 - Contribuição da fonte de renda na desigualdade de renda total: fontes de renda zona rural de Mato Grosso: 2004 e 2006

\begin{tabular}{lcc}
\hline \multirow{2}{*}{ Renda } & \multicolumn{2}{c}{ Participação da fonte de renda na desigualdade de renda total $\left(\mathrm{I}_{\mathrm{k}}\right)$} \\
\cline { 2 - 3 } & 2004 & 2006 \\
\hline Agrícola & 0,6369 & 0,6010 \\
Não Agrícola & 0,2072 & 0,1948 \\
Aposentadorias e Pensões & 0,1086 & 0,1602 \\
Juros e Aluguéis & 0,0270 & 0,0214 \\
Trabalho Secundário e Outros Trabalhos & 0,0202 & 0,0227 \\
\hline
\end{tabular}

Fonte: Elaboração própria com base na Pesquisa Nacional por Amostras de Domicílios (Microdados) (IBGE): 2004 e 2006 
Observa-se que, a despeito de exibir trajetória levemente cadente entre os dois anos, a renda Agrícola é a que mais afetou a desigualdade da renda total. Em seguida, tem-se a renda Não Agrícola, e Aposentadorias e Pensões. Em especial, Juros e Aluguéis, além de Trabalho Secundário e Outros Trabalhos, responderam por reduzida participação na desigualdade de renda total, tanto em 2004, quanto em 2006. Esses resultados confirmam de maneira parcial a hipótese do trabalho.

\section{Indicadores de pobreza}

Analisam-se os seguintes índices de pobreza da população residentes em áreas rurais em MT: proporção de pobres $(\mathrm{H})$, hiato ou incidência da pobreza (I) e o índice de pobreza (P) de Sen. Antes, contudo, na Tabela 7 consta resumo de estatísticas da pobreza entre as famílias rurais mato-grossenses.

Tabela 7 - Estatísticas descritivas da pobreza: zona rural de Mato Grosso: 2004 e 2006

\begin{tabular}{lcc}
\hline \multicolumn{1}{c}{ Estatísticas } & 2004 & 2006 \\
\hline Linha de Pobreza - Z & $\mathrm{R} \$ 130,00$ & $\mathrm{R} \$ 175,00$ \\
Números de Famílias & 600 & 638 \\
Pobres - K & & \\
$\begin{array}{l}\text { Número Total de } \\
\text { Famílias - N }\end{array}$ & 1.506 & 1.555 \\
\hline
\end{tabular}

Fonte: Elaboração própria com base na Pesquisa Nacional por Amostras de Domicílios (Microdados) (IBGE): 2004 e 2006

Recorda-se que a linha de pobreza adotada, metade do salário mínimo vigente em cada ano, foi de R\$130,00 em 2004 e de R\$175,00 em 2006. De acordo com a PNAD de 2004, com base na amostra de 1.506 famílias residentes nas áreas rurais, 600 delas tinham renda mensal per capita inferior a R \$ 130,00. Por seu turno, em 2006, 638 das 1.555 famílias (amostra) nas regiões rurais de MT, auferiram renda inferior a R\$ $175,00^{6}$. Recorda-se que, nesse caso, a hipótese foi que, de 2004 a 2006, houve expansão da pobreza rural em Mato Grosso. Anotam-se estatísticas sobre essa categoria na Tabela 8.

A proporção de famílias pobres foi de quase 40\% em 2004 e de aproximadamente 41\% em 2006. Nota-se também que, enquanto o hiato ou incidência de pobreza, tanto em 2004 quanto em 2006, se aproximou de $38 \%$, o índice de pobreza de Sen em 2004 registrou valor levemente menor que $21 \%$, inferior, entretanto, ao índice alusivo a 2006. Dessa forma, entre 2004 ${ }^{6} \mathrm{~A}$ partir da expansão dessas amostras obtém-se: em 2004: 525.500 e em 2006: 560.250 famílias residentes nas áreas rurais de Mato Grosso, equivalentes, nos dois casos, a aproximadamente um terço das famílias do Estado como um todo
Tabela 8 - Indicadores de pobreza entre famílias rurais de Mato Grosso: 2004 e 2006

\begin{tabular}{lcc}
\hline & \multicolumn{2}{c}{ Índices de Pobreza } \\
\hline \multicolumn{1}{c}{ Indicadores } & 2004 & 2006 \\
\hline $\begin{array}{l}\text { Proporção de } \\
\text { Famílias Pobres }\end{array}$ & $39,84 \%$ & $41,02 \%$ \\
$\begin{array}{l}\text { Hiato ou Incidência } \\
\text { de Pobreza }\end{array}$ & $38,64 \%$ & $38,87 \%$ \\
$\begin{array}{l}\text { Índice de Pobreza de } \\
\text { Sem }\end{array}$ & $20,77 \%$ & $22,33 \%$ \\
\hline
\end{tabular}

Fonte: Elaboração própria com base na Pesquisa Nacional por Amostras de Domicílios (Microdados) (IBGE): 2004 e 2006

e 2006, os dados amostrais sugerem que a pobreza entre as famílias rurais mato-grossense experimentou elevação, ratificando hipótese previamente formulada. Por oportuno, relembra-se: o índice de pobreza de Sen, além da proporção dos pobres e da incidência ou intensidade da pobreza, também incorpora a desigualdade da distribuição de renda entre os pobres.

\section{Conclusões}

1. Resumindo-se os resultados mais relevantes, verificou-se que a renda Agrícola exerce supremacia no conjunto das várias fontes de renda, responde pelo maior incremento sobre a renda total, exibe alta desigualdade nas distribuições de renda relevantes às análises, pressiona para cima e explica a parcela mais representativa da desigualdade. Ademais, a percentagem das famílias que recebem a renda Agrícola é superior às frações das outras fontes. Finalmente, os valores obtidos sugerem que a pobreza entre as famílias rurais ascendeu entre 2004 e 2006;

2. Esses resultados derivam de uma economia que, inserta em ambiente global cada vez mais competitivo, alicerçada em estrutura fundiária com elevada concentração, vem exibindo expressivo dinamismo do seu produto interno bruto, onde a atividade agropecuária, nucleada em modelo primário-exportador (com predominância da produção in natura de soja), responde pela maior parcela desse agregado, além de exercer importante e estratégica função na economia do Estado como um todo. Além desse núcleo, não se pode esquecer que outras culturas, como a de algodão, milho e arroz, além da pecuária, também contribuíram para a obtenção dos resultados anteriormente citados. A agropecuária matogrossense, de modo geral, abriga elevado número de latifúndios modernos que adotam inovações tecnológicas dominantemente extensivas em mão-de-obra. A cultura 
do algodão, em particular, é relativamente mais intensiva no uso do fator de produção trabalho;

3. Os eixos centrais do modelo econômico ora vigente nessa unidade federativa estão causando diversos resultados sobre indicadores sociais, ou seja, os caracteres correntes da economia mato-grossense, centrada na atividade rural, moldam contexto pautado por elevada desigualdade de distribuição de renda e, como as estatísticas estimadas sugerem, pelo incremento da pobreza no campo;

4. A interação entre os grandes estabelecimentos agropecuários com as pequenas unidades rurais campesinas, intrínseco ao processo de expansão de fronteira agrícola como o atualmente vivenciado pela economia mato-grossense, pode estar causando acentuada desintegração das pequenas unidades campesinas, contribuindo, nessess termos, para o incremento da desigualdade e da probreza na zona rural. Uma vez mais, a dinâmica dessa expansão da fronteira agrícola está causando vários efeitos à agropecuária regional: um deles é representado pela contínua e crescente reprodução e consolidação do latifúndio, cujos movimentos foram ampliados pela expropriação dos pequenos produtores, ou seja, pela dissolução da propriedade privada fundada no próprio trabalho;

5. Outrossim, não se pode esquecer que as políticas sociais compensatórias atualmente sendo praticadas pelo Governo Federal, tipificadas em programas de transferência de renda, como o Bolsa Família, podem estar contribuindo para reduzir a desigualdade e a pobreza, sejam nas áreas urbanas, seja nas áreas rurais do Estado. Entrementes, em particular na economia de MT, inexistem estudos que tenham investigado esse assunto com acuidade;

6. É relevante se destacar, por fim, que a recorrência às categorias de análises da corrente economia matogrossense, centrada no modelo primário exportador de soja in natura e com participação relevante de outras atividades agropastoris, por óbvio, não garante precisão absoluta às análises, em especial, na identificação das principais causas da ascensão da desigualdade e da pobreza no campo. Não se tem dúvida que as categorias citadas exercem poder explanatório relevante. Porém, a identificação do peso ou do grau de importância de cada desses elementos empíricos ainda requer muito esforço dos pesquisadores regionais.

\section{Referências}

ARAÚJO, J. A.; FEITOSA, D. G.; BARRETO, F. A. F. Determinantes da desigualdade de renda em áreas rurais do
Nordeste. Revista de Política Agrícola. Brasília: Ano XVII, n. 04, 2008.

BARROS, R. P. et al. Uma avaliação dos impactos do salário mínimo sobre o nível de pobreza metropolitana no Brasil. Revista de Economia (ANPEC), Niterói, v. 2, n. 1, 2001.

BARROS, R. Uma análise das principais causas da queda recente na desigualdade de renda brasileira. Econômica, Rio de Janeiro, v. 8, n. 1, p. 117-148, 2006.

FEI, J. C.; RANNIS, G.; KOU, S. W. Y. Growth and family distribution of income by factor components. Quartely Journal of Economics, XCII, p. 17-53, 1978.

FERREIRA, F. H. G. et al. Ascensão e queda da desigualdade de renda no Brasil. Econômica, Rio de Janeiro, v. 8, n. 1, p. 149-171, 2006.

GRASEL, D. et al. Desigualdade, pobreza e crescimento: uma análise comparativa entre Mato Grosso e Santa Catarina. Textos de Economia, v. 11, p. 54-78, 2008.

HOFFMANN, R., NEY, M. G. Origem Familiar e Desigualdade de Renda na Agricultura. Pesquisa e Planejamento Econômico, v. 33, n. 3, p. 541-572, 2003.

HOFFMANN, R. Estatística para Economistas. 4. ed. São Paulo: Thompson, 2006, 432 p.

INSTITUTO BRASILEIRO DE GEOGRAIA E ESTATÍSTICA - IBGE. Base de dados da Pesquisa Nacional por Amostra de Domicílios (Microdados/PNAD). Rio de Janeiro, 2004. CD-ROM.

INSTITUTO BRASILEIRO DE GEOGRAIA E ESTATÍSTICA - IBGE. Base de dados da Pesquisa Nacional por Amostra de Domicílios (Microdados/PNAD). Rio de Janeiro, 2006. CD-ROM.

MARIANO, J. L.; NEDER, H. D. Renda e pobreza entre famílias no meio rural do Nordeste. In: IX Encontro Nacional de Economia Política, Uberlândia: Anais..., Uberlândia: Associação Nacional de Economia Política, 2004. p. 156-170.

MATIAS, G. D. V.; SILVA, L. M. R.; KHAN, A. S. Perfil dos produtores de frutas do Município de Limoeiro do Norte-CE frente ao novo paradigma de desenvolvimento do setor. Revista Ciência Agronômica, v. 34, n. 01, p. 5-11, 2003.

NEDER, H. D. Os Efeitos das Atividades Não Agrícolas na Distribuição de Renda do Meio Rural do Brasil. Revista de Economia e Sociologia Rural, v. 41, n. 2, p.259-278, 2003.

NEDER, H. D.; SILVA, J. L. M. Pobreza e distribuição de renda em áreas rurais: uma abordagem de inferência. Revista de Economia e Sociologia Rural, Brasília, v. 42, n. 03, p. 35-45, 2004.

PEREIRA, B. D.; MENDES, C. M.; A Modernização da agricultura de Mato Grosso. Revista de Estudos Sociais, Cuiabá, ano 04, n. 7, 2002.

PEREIRA, B. D. et al. Mato Grosso: agribusiness e outras análises. Revista Mato-grossense de Geografia, Cuiabá, Ano 11, n. 9, p. 67-74, 2006. 
PEREIRA, B. D. et al. Especialização e vantagens competitivas de Mato Grosso no mercado internacional: um estudo de indicadores de comércio exterior no período 1996-2007. Revista de Economia do Paraná, Curitiba, v. 35, n. 3, 2009.

PEREIRA, B. D. A Agricultura de Mato Grosso: velhas questões de uma nova economia, Cuiabá: EdUFMT, 2010. Mimeo.

PESQUISA NACIONAL POR AMOSTRAS DE DOMICÍLIOS: PNAD (Microdados). Rio de Janeiro: IBGE, 2004.

PESQUISA NACIONAL POR AMOSTRAS DE DOMICÍLIOS: PNAD (Microdados). Rio de Janeiro: IBGE, 2006.

RIBEIRO, C. O.; MENEZES, R. G. Políticas públicas, pobreza e desigualdade no Brasil. Revista Textos e Contextos, Porto Alegre, v. 7, n. 1, p. 42-55, 2008.
ROCHA, S. Pobreza no Brasil. Revista de Economia (ANPEC), Niterói: v. 2, n. 1, 2001.

SCHNEIDER, S. A pluriatividade como estratégia de reprodução social da agricultura familiar no Sul do Brasil. Estudos Sociedade e Agricultura, Rio de Janeiro: v. 16, p. 164-184, 2001.

SON, H. H. A Note on Pro-Poor Growth. Economic Letters, v. 82, p. 307-314, 2004.

VEIGA, J. E. et al. O Brasil rural precisa de uma estratégia de desenvolvimento. Brasília: Convênio FIPE-IICA (MDA/ CNDRS/NEAD), 2001. 108 p.

VIANA, et al. Competitividade do Ceará no mercado internacional de frutas: o caso do melão. Revista Ciência Agronômica, Fortaleza, v. 37, n. 1, p. 25-31, 2006. 